\title{
BKCa participates in E2 inducing endometrial adenocarcinoma by activating MEK/ERK pathway
}

\author{
Fenfen Wang ${ }^{1 \dagger}$, Qin Chen ${ }^{2 \dagger}$, Genping Huang ${ }^{1}$, Xuedong Guo ${ }^{1}, \mathrm{Na} \mathrm{Li}^{1}$, Yang Li ${ }^{1}$ and Baohua $\mathrm{Li}^{1 *}$ (D)
}

\begin{abstract}
Background: The large-conductance, voltage-gated, calcium (Ca (2+))-activated potassium channel (BKCa) plays an important role in regulating $\mathrm{Ca}(2+)$ signaling and cell physiological function, and is aberrantly expressed in some types of cancers. The present study focuses on identifying the oncogenic potential and clinical significance of BKCa in endometrial adenocarcinoma, as well as exploring the mechanistic relevance by $17 \beta$-estradiol (E2) inducing aberrant activation of MEK1/2 and ERK1/2 via BKCa.

Methods: The expression of BKCa, ERK1/2 and p-ERK1/2 were examined by immunohistochemical staining in 263 cases, including 185 primary types I endometrial cancer tissues, 38 atypical endometrial hyperplasia tissues and 40 normal endometrium tissues. Cell growth, cycle, apoptosis rate, migration and invasion was separately tested in Ishikawa cells using siRNA-BKCa and/or E2 treatment, as well as the expression of these interested proteins by western blot analysis.
\end{abstract}

Results: We showed that expression of BKCa is significantly elevated in 185 types I endometrial adenocarcinoma tissues compared to those of the normal endometrium and atypical endometrial hyperplasia tissues. Furthermore, in vitro observations revealed that down-regulation of BKCa expression inhibited cell growth by both enhancing apoptosis and blocking G1/S transition, suppressed cell migration and invasion in Ishakiwa cells, and decreased the expression of p-MEK1/2 and p-ERK1/2. Additionally, RNAi-mediated knockdown of BKCa attenuated the increased cellular growth and invasion, as well as the elevated expression of p-MEK1/2 and p-ERK1/2 proteins, induced by E2 stimulation. More importantly, the aberrant expression of BKCa and p-ERK1/2 were closely related with poor prognostic factors in type I endometrial cancer, and up-regulated expression of p-ERK1/2 was significantly associated with shorter disease-free survival (DFS) and overall survival (OS) and was an independent prognostic factor in type I endometrial cancer patients.

Conclusion: Our results demonstrated that BKCa and the key downstream effectors p-ERK1/2 could be involved in important signaling pathways in initiation and development of endometrial adenocarcinoma and may provide a new therapeutic approach for women with endometrial cancer.

Keywords: Endometrial adenocarcinoma, BKCa, MEK1/2, ERK1/2, 17ß-estradiol, Prognosis

\footnotetext{
*Correspondence: Ibh19787@zju.edu.cn; Ibh8888@163.com

${ }^{\dagger}$ Fenfen Wang and Qin Chen contributed equally to this work.

'Department of Gynecologic Oncology, Women's Hospital, Zhejiang

University, School of Medicine, Xueshi Road 1, Hangzhou, Zhejiang 310006,

People's Republic of China

Full list of author information is available at the end of the article
}

(c) The Author(s). 2018 Open Access This article is distributed under the terms of the Creative Commons Attribution 4.0 International License (http://creativecommons.org/licenses/by/4.0/), which permits unrestricted use, distribution, and reproduction in any medium, provided you give appropriate credit to the original author(s) and the source, provide a link to the Creative Commons license, and indicate if changes were made. The Creative Commons Public Domain Dedication waiver (http://creativecommons.org/publicdomain/zero/1.0/) applies to the data made available in this article, unless otherwise stated. 


\section{Background}

Endometrial cancer (EC) is one of the most common malignancies of the female genital tract worldwide. It is grouped into two subtypes; type I, an estrogen-dependent endometrial adenocarcinoma which is associated with a slow progression and good prognosis, whilst type II is characterized as an aggressive non-estrogenic endometrial cancer with a poor prognosis. In general, type I is the most common endometrial cancer subtype [1].

Patients with EC are often diagnosed as early stage, and the best method to balance optimal survival with minimal adverse effects on quality of life has not yet been defined. The 5-year overall survival ranges from 74 to $91 \%$ in patients without metastatic disease [1], but the recurrence rate and mortality remains high [2]. Imbalance of estrogen and progesterone leading towards a hyper estrogenic state has been determined to increase the risk of endometrial adenocarcinoma. The mechanisms by which estrogen stimulates the endometrium from atypical endometrial hyperplasia to develop cancer are still unclear. Several studies have demonstrated that abnormal activation of PKC $\beta$ /ERK pathway [3], K-Ras/ PKC $\beta$ [4], PI3K/AKT [5] induced by estrogen were involved in the process. However, the concrete mechanisms by which E2 induces the initiation and progression of endometrial adenocarcinoma have not been fully elucidated. The current study aimed to explore the mechanisms of E2 inducing type I endometrial carcinogenesis and cancerous development, and the related molecular pathway in order to identify a potential new approach for treatment.

The large-conductance, voltage-gated, calcium (Ca (2 $+)$ )-activated potassium channel (BKCa) is encoded by the KCNMA1 gene and characterized by a large conductance to potassium, plays an important role in regulating $\mathrm{Ca}(2$ +) signaling and associates with cell membrane potential and cell metabolism [6, 7]. The altered expressions or activation of $\mathrm{BKCa}$ may lead to changes of intracellular calcium and membrane potential resulting in dysfunction of cells and organs. BKCa was revealed as an important molecule in regulating contraction/relaxation of muscle cells [8], neurotransmission in the brain, and metabolism, proliferation, migration, and gene expression [9]. Although it has been described in some types of cancer cell, such as osteosarcoma [10], breast cancer [11] and gastric cancer [12], little is known about the functions of $\mathrm{BKCa}$ in uterus. BKCa was studied in uterus smooth muscle and was reported that $\mathrm{BKCa}$ is over expressed in adenomyosis tissues, and it might cause abnormal muscle contractility that induces the inflammation effects, endometrium impairment and pain [13]. Moreover, the expression of $\mathrm{BKCa}$ in pregnant myometrium is reduced during labor and related with onset of parturition [14, 15]. Recently, Li et al. [16] reported the role of $\mathrm{BKCa}$ in endometrial cancer
HEC-1-B cells. They demonstrated that forced expression of $\mathrm{BKCa}$ could induce proliferation and migration, and the specific opener (NS1619) or blocker (IBTX) of BKCa could regulate the cellular biological behavior. This shows that $\mathrm{BKCa}$ could confer growth and migration advantage to endometrial cancer cells. However, there are still no other reports or further investigations about the roles and mechanisms of $\mathrm{BKCa}$ in endometrial cancer, especially in the most common subtype endometrial adenocarcinoma.

In the present study, we confirmed elevated expression of $\mathrm{BKCa}$ in type I endometrial cancer tissues compared to those in normal endometrium and atypical endometrial hyperplasia tissues, and demonstrated that downregulated expression of $\mathrm{BKCa}$ influenced the cell growth and invasiveness via inactivation of the MEK/ERK pathway. We propose that $\mathrm{BKCa}$, is a membrane protein that not only controls the physiological effects of the endometrial cells, but also participates in the initiation and progression of endometrial adenocarcinoma by E2 stimulation.

\section{Methods \\ Cell culture and siRNA preparation}

Human endometrial adenocarcinoma cell line Ishikawa with functional Estrogen Receptor (ER) was purchased from Procell Life Science \& Technology Co.,Ltd. (Wuhan, China) (Catalogue numbers: CL-0283) and was further transfected using $50 \mathrm{nM}$ siRNA-BKCa or scramble siRNA. Additional file 1: Table S1 shows sequences of siRNA.

\section{E2 treatment}

17ß-estradiol (E2) were purchased from Sigma Company, and dissolved in phosphate buffer solution (PBS) at $1 \mathrm{nM}$ concentration. Then, Ishikawa cells were treated with $1 \mathrm{nM}$ E2 for further study.

\section{RNA extraction and PCR}

Total RNA of cultured cells was isolated by using Trizol reagent. Reverse transcription was performed with the procedure as described previously [17]. PCR reactions for gene expression were performed using SYBR green RT-PCR kit. The primer pairs of $\mathrm{BKCa}$ are listed in Additional file 1: Table S1.

\section{Western blotting analysis}

Ishikawa cell lysates were boiled with gel-loading buffer for $5 \mathrm{~min}$ at $100{ }^{\circ} \mathrm{C}$, resolved on $10 \%$ SDS-PAGE, transferred to PVDF membranes, probed with appropriate antibodies and visualized with enhanced chemiluminescence (ECL). The detailed antibodies information is listed in Additional file 2: Table S2.

\section{CCK-8 assay}

Ishikawa cells were plated in the 96 well plates at a density of 5000 cells per well. At the end of each indicated 
time point $(0,24,48$, and $72 \mathrm{~h}$ post-transfection), cells were incubated with CCK-8 $(5 \mathrm{mg} / \mathrm{mL})$ for $4 \mathrm{~h}$ at $37{ }^{\circ} \mathrm{C}$ and the absorbance read at $570 \mathrm{~nm}$ using a micro-plate reader. Each treatment was performed triplicates and each experiment was repeated twice.

\section{Migration and invasion assay}

Migration and invasion assays were carried out as described previously. For migration assays, $5 \times 10^{4}$ cells suspended in $200 \mu \mathrm{l}$ serum free medium were plated in the upper chamber and incubated at $37{ }^{\circ} \mathrm{C}$ for $12 \mathrm{~h}$, while for the invasion assay, $9 \times 10^{4}$ cells suspended in $300 \mu \mathrm{l}$ serum free medium were plated in the upper chamber and incubated at $37^{\circ} \mathrm{C}$ for $24 \mathrm{~h}$. Non-invading or migrating cells were scrubbed with a cotton-tip swab and the cells that penetrated through the filter were stained with crystal violet and counted at a magnification of $\times 200$ in randomly selected fields by using a phase-contrast microscope, and the mean number of cells per field was calculated.

\section{Flow cytometry for cell cycle and apoptosis analysis}

Flow cytometry was used to determine cell cycling progression and apoptosis analysis with procedure as described previously. For cell cycling analysis, at $48 \mathrm{~h}$ post-transfection, the cells $\left(3 \times 10^{5}\right.$ cells/well $)$ were collected by trypsinization and fixed with ice-cold ethanol $(75 \%)$ at $-20{ }^{\circ} \mathrm{C}$ for $24 \mathrm{~h}$. Then, fixed cells were incubated in a propidium iodide/PBS staining buffer $(20 \mu \mathrm{g} /$ $\mathrm{ml}$ propidium iodide, $100 \mu \mathrm{g} / \mathrm{ml}$ RNase A, and $0.1 \%$ Triton $\mathrm{X}-100)$ at $37{ }^{\circ} \mathrm{C}$ for $30 \mathrm{~min}$. Data were acquired using Cell Quest software, and the percentages of G0/ G1, S, and G2/M phase cells were calculated. For cell apoptosis assays, at $48 \mathrm{~h}$ post-transfection of cells $(3 \times$ $10^{5}$ cells/well), Annexin- $\mathrm{V}$ and propidium iodide was added to the cells and samples were analyzed within 30 min after staining. Quantification of fluorescence was analyzed by flow cytometry.

\section{Patients and immunohistochemical staining}

The retrospective study enrolled 263 patients, including 185 primary type I endometrial cancer and 38 atypical endometrial hyperplasia tissues, with complete medical record information at Women's Hospital of Zhejiang University, from January 2007 to December 2009. 40 patients with normal endometrial tissues that underwent the total hysterectomy because of gynecological benign diseases served as controls. The methods of tissue specimen preparation and immunohistochemistry staining performing were described previously [18]. BKCa, ERK1/ 2 and p-ERK1/2 immunoreactivities were assessed by staining intensity and positively stained distribution of the tumor cells. In brief, staining intensity was scored as negative (0), weakly positive (1), moderately positive (2) or strongly positive (3). The positively stained distribution was scored as 0 for $<0-5 \%, 1$ for $6-25 \%, 2$ for $26-$ $50 \%, 3$ for $51-75 \%$, and 4 for $>75 \%$ positively stained cells. Finally, the intensity score and distribution score were multiplied to yield an overall score. A total score $<$ 4 was considered as low expression and $\geq 4$ as high expression.

\section{Follow-up}

The patients with type I endometrial cancer were followed up postoperatively by interview at the clinic or by phone call. Regional tumor recurrence, distant metastasis, and patient survival were recorded. Disease-free survival (DFS) and overall survival (OS) were calculated from the day of the surgery until disease recurrence or death. The last day of follow-up was December 2016. The mean follow-up was 94.7 months (range 14120 months). There were 33 recurrences $(33 / 185,17.8 \%)$ and 30 deaths $(30 / 185,16.2 \%)$.

\section{Statistical analysis}

Statistics were assessed using software packages SPSS version 22.0. For in vitro experiments, a student's t-test was used to analyze the differences between two groups. The results were presented as Mean $\pm \mathrm{SD}$. Correlations between protein expression and the clinic-pathological parameters and significant differences in protein expression were determined by Pearson's chi-square test. Survival curves were generated by the Kaplan-Meier method and survival rates were compared using the log-rank test. On the univariate and multivariate analyses, the Cox proportional hazard method was used to identify independent predictors of survival. All statistical tests were two-sided, and $p$-values 0.05 were considered statistically significant $(*<0.05, * * 0.01)$.

\section{Results}

Knockdown of BKCa expression influenced the biological effects of Ishikawa cells

To investigate the role of BKCa expression in initiation and progression of endometrial adenocarcinoma, we explored the effects of altered expression of BKCa on biological functions of Ishikawa cells. First, we knocked down the expression of BKCa using siRNA, and compared with the negative control. The siRNA targeting BKCa effectively down-regulated the mRNA and protein levels of BKCa at $48 \mathrm{~h}$ post-transfection (Fig. 1a, b). We also examined the effects on cellular proliferation using CCK-8 assay, which revealed that inhibition of BKCa expression reduced the proliferation of Ishikawa cells at $48 \mathrm{~h}$ and $72 \mathrm{~h}$ post-transfection $(p=0.035, p=0.005)$ (Fig. 1c). Secondly, we observed that cell apoptosis was induced by inhibition of BKCa expression in Ishikawa cells as assessed by an Annexin V \& PI apoptosis detection kit. 


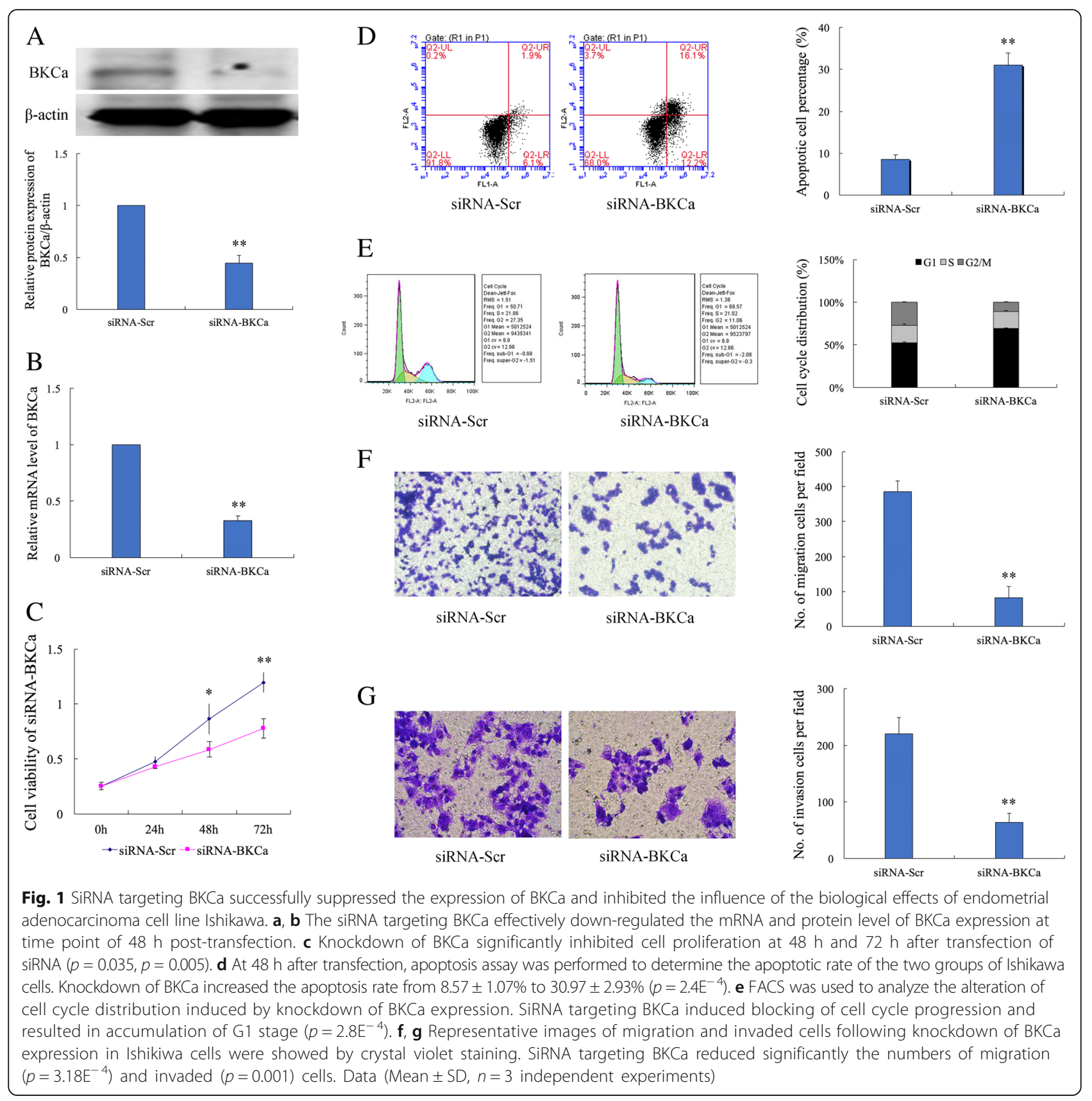

The inhibition of $\mathrm{BKCa}$ led to increased apoptotic response, and the apoptotic cell rate was significantly elevated compared to the control group $\left(p=2.4 \mathrm{E}^{-4}\right)$ (Fig. 1d). In consistent with apoptosis results, we simultaneously performed the cell cycle pattern by using PI staining and found that down-regulated expression of $\mathrm{BKCa}$ triggered a significant accumulation of cells in G1 phase and reduced the percentage of cells in $S$ and G2/M phase (Fig. 1e). This result suggested that BKCa could promote cell growth through influencing cell cycle progression and apoptosis rate. Finally, we determined the effect of $\mathrm{BKCa}$ on migratory and invasive capacity in Ishikawa cells using transwell assay. Down-regulated expression of BKCa inhibited the cell migration $\left(p=3.18 \mathrm{E}^{-4}\right)$ and impaired the invasive capacity $(p=0.001)$ (Fig. 1f, g). These observations further support an important role of $\mathrm{BKCa}$ in growth and invasiveness of endometrial adenocarcinoma cells and could act as an oncogenic factor contributing to initiation and progression of endometrial adenocarcinoma.

\section{E2 induced the increase of BKCa expression in Ishikawa cells and promoted cell growth and invasion}

Estrogen-ER signaling pathways were found to be crucial for endometrial adenocarcinoma development, and as a 
steroid hormone E2 was strongly related with the hormone dependent type I endometrial cancer. After stimulating with $1 \mathrm{nM} \mathrm{E2}$, the proliferation of Ishikawa cells was increased significantly at 48 and $72 \mathrm{~h}(p=0.019, p=0.011)$ (Additional file 3: Figure S1B), and the rate of apoptosis was decreased when compared to the negative control $(p=0.006)$ (Additional file 3: Figure S1C). Additionally, E2 promoted cell cycle progression through G1 phase (Additional file 3: Figure S1D), and also enhanced the migration $\left(p=5.2 \mathrm{E}^{-5}\right)$ and invasive capacity $\left(p=4.87 \mathrm{E}^{-4}\right)$ of Ishikawa cells (Additional file 3: Figure S1E, F). The MEK/ERK pathways are important molecules in the process of E2 promoting endometrial adenocarcinoma, and the phosphated modifications of MEK1/2 and ERK1/2 are the main active forms for signal

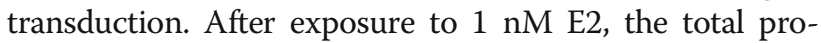
teins were extracted from the Ishikawa cells, and the interested molecules were examined using western blot. We found that expression of BKCa protein $(p=0.013)$ was significantly up-regulated when compared to the control group. Importantly, the total MEK $1 / 2$ and ERK $1 / 2$ protein levels were unchanged, whereas the expression of $\mathrm{p}$-MEK $1 / 2(p=0.049)$ and p-ERK1/2 $(p=0.044)$ were elevated significantly in Ishikawa cells exposed to $1 \mathrm{nM}$ E2 (Additional file 3: Figure S1A). It suggested that E2 could phosphorylate and active MEK/ERK pathway, leading to effects on a variety of physiologic and development processes in endometrial adenocarcinoma cells. More importantly, the molecular mechanism might be partly dependent regulation of BKCa.

\section{Knockdown of BKCa attenuated up-regulation of MEK/ ERK phosphylation and promotion of Ishikawa growth and invasiveness induced by E2 stimulation}

The possibility that $\mathrm{BKCa}$ is involved in the process of E2 activating MEK/ERK pathway is still unclear. To investigate the role of $\mathrm{BKCa}$ in the molecular mechanism induced by E2, we firstly knocked down the expression of $\mathrm{BKCa}$ in Ishikawa cells using siRNA technique, the mRNA and protein expression levels of BKCa were inhibited significantly, meanwhile decreased BKCa expression resulted in the reduction of phosphorylation of MEK1/2 $\left(p=2.96 \mathrm{E}^{-4}\right)$ and ERK1/2 ( $p$ $=0.001)$, no change of total MEK $1 / 2$ and ERK1/2 protein (Additional file 4: Figure S2A, B). The results showed that BKCa could regulate and activate MEK/ ERK pathway in Ishikawa cells. Furthermore, we found that when E2 was used to stimulate the cell growth, the siRNA scramble control group demonstrated increased phosphorylation levels of MEK1/2 and ERK1/ 2 compared to that without E2 stimulation. However, down-regulation of $\mathrm{BKCa}$ with siRNA attenuated increased phosphorylation of MEK1/2 $(p<0.01)$ and ERK1/2 $(p<0.01)$ induced by E2 (Fig. 2a). This suggested $\mathrm{BKCa}$ may be an important middle membrane molecule in the process of E2 activating MEK/ ERK pathway. Here, we have shown that BKCa plays an important role in growth and invasiveness of Ishikawa cells. When knockdown of BKCa expression using siRNA, that resulted in increased proliferation (Fig. 2b), migration and invasion in Ishikawa cells stimulated by E2 was all reversed accordingly (Fig. 2e, f) $(p<0.05)$. Moreover, the decreased apoptosis and the altered cell cycle distribution have been attenuated(Fig. $2 \mathrm{c}, \mathrm{d})(p<0.01)$. This suggests that BKCa could be an essential middle molecular involved in E2 stimulating physiologic and development processes in Ishikawa cells via activating MEK/ERK pathway.

\section{BKCa and p-ERK proteins closely related with} clinicopathological characteristics and prognosis in 185 cases with type I endometrial cancer

We have shown that down-regulation of BKCa expression could induce a decrease in MEK1/2 and ERK1/2 phosphorylation in our study, and ERK was key effector in the pathway. Therefore, immunohistochemistry staining was performed to detect the proteins of $\mathrm{BKCa}$, ERK1/2 and p-ERK1/2 in 263 endometrial tissue samples, including 185 type I endometrial cancer, 40 normal endometrial tissues and 38 atypical endometrial hyperplasia tissues. The detailed information of endometrial adenocarcinoma patients was shown in Additional file 5: Table S3.

The representative immunohistochemical staining of BKCa, ERK1/2 and p-ERK1/2 expression is shown in Fig. 3. The majority expressions of endometrial adenocarcinoma tissue showed consistent, strong staining of BKCa of cell membranous throughout all layers. BKCa expression was significantly elevated in endometrial adenocarcinoma tissues compared to those of normal endometrium $\left(p=8.4 \mathrm{E}^{-}\right.$ $\left.{ }^{5}\right)$ and atypical endometrial hyperplasia $\left(p=1.39 \mathrm{E}^{-4}\right)$ (Table.1). There was no significant different in the expression levels of $\mathrm{BKCa}$ between the atypical endometrial hyperplasia tissue group and the normal endometrium tissues group $(p>0.05)$. As the key effector molecules on MEK/ERK pathway, the staining of ERK1/2 and p-ERK1/2 was predominantly located in the cytoplasm and nuclear of tumor cells, and they were both over-expressed in endometrial adenocarcinoma compared to normal endometrium $\left(p=4.19 \mathrm{E}^{-10}, p=2.77 \mathrm{E}^{-8}\right)$ and atypical endometrial hyperplasia tissues $\left(p=1.97 \mathrm{E}^{-7}, p=0.036\right)$ (Table.1). Between atypical endometrial hyperplasia group and normal endometrial group, only the expression of p-ERK $1 / 2$ was significantly increased in atypical endometrial hyperplasia $(p=$ 0.001), and the expression of ERK1/2 showed no significant differences (Table.1). Further investigations about the correlations of the proteins and the clinico-pathological parameters were analyzed in endometrial adenocarcinoma group. 


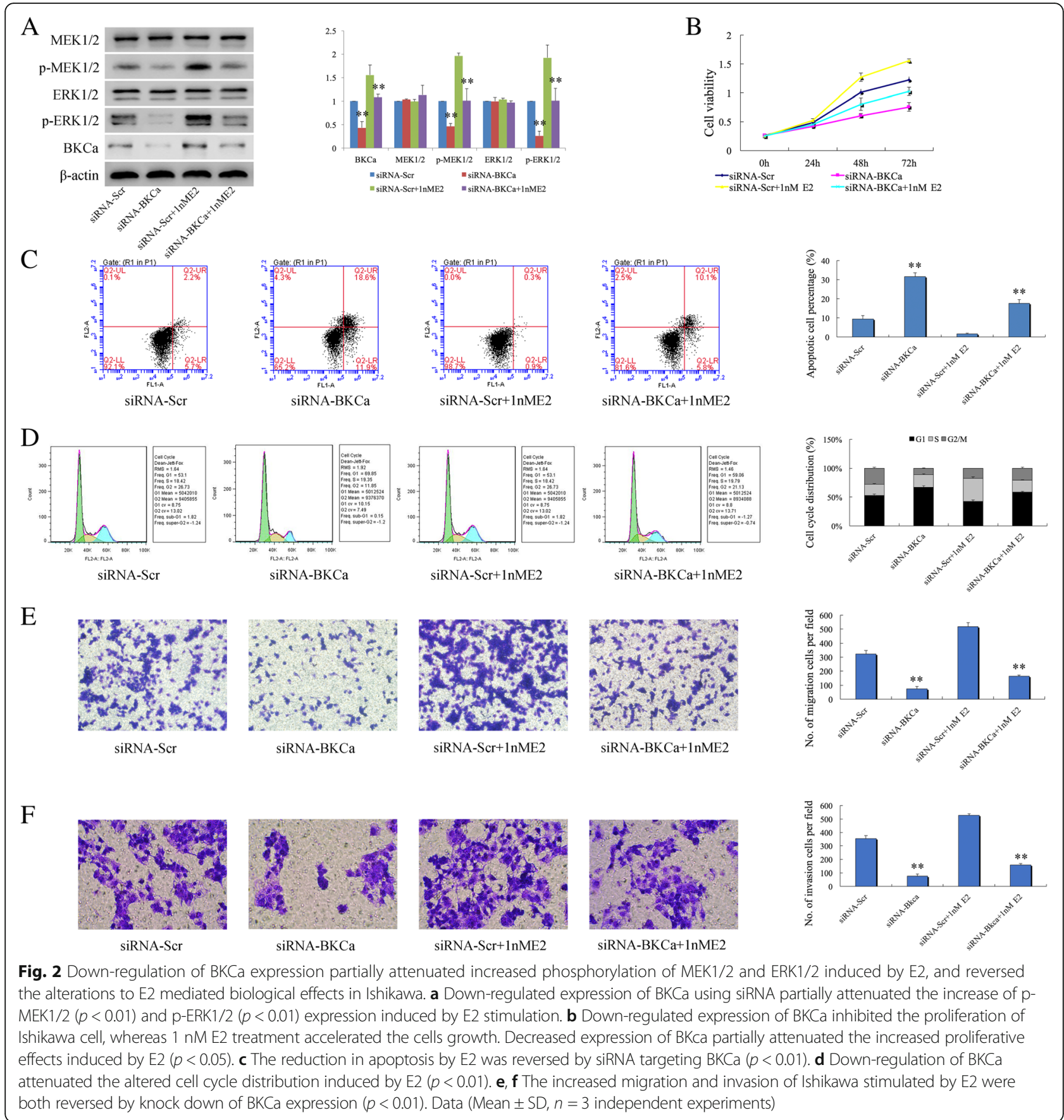

The Pearson chi-square test showed that expressions of ERK $1 / 2$ and p-ERK1/2 were positively correlated with BKCa expression $(p=0.001, p=0.038)$ (Table.2). The correlations between the three interested molecules and clinic-pathological parameters in 185 endometrial adenocarcinoma tissues were evaluated by Pearson's chi-square test. The results from Table. 3 showed that the elevated $\mathrm{BKCa}$ expression was significantly associated with FIGO stage $\geq \mathrm{II}(p=0.004)$ and lymph node metastasis (LNM) ( $p$ $=0.011)$. Although ERK1/2 expression was not associated with any clinic-pathological characteristics, the high expression of p-ERK $1 / 2$ was significantly related to FIGO stage $\geq$ II $(p=0.012)$, cervical stromal involvement $(p=0.014)$, LVSI $(p=0.046)$ and LNM $(p=0.018)$ (Table.3). It suggested that aberrant expression of BKCa and p-ERK1/2 was closely related with poor prognostic factors in type I endometrial cancer samples.

Kaplan- Meier analysis was used to investigate the prognostic value of the three proteins. The survival curves showed the association of expression of three 


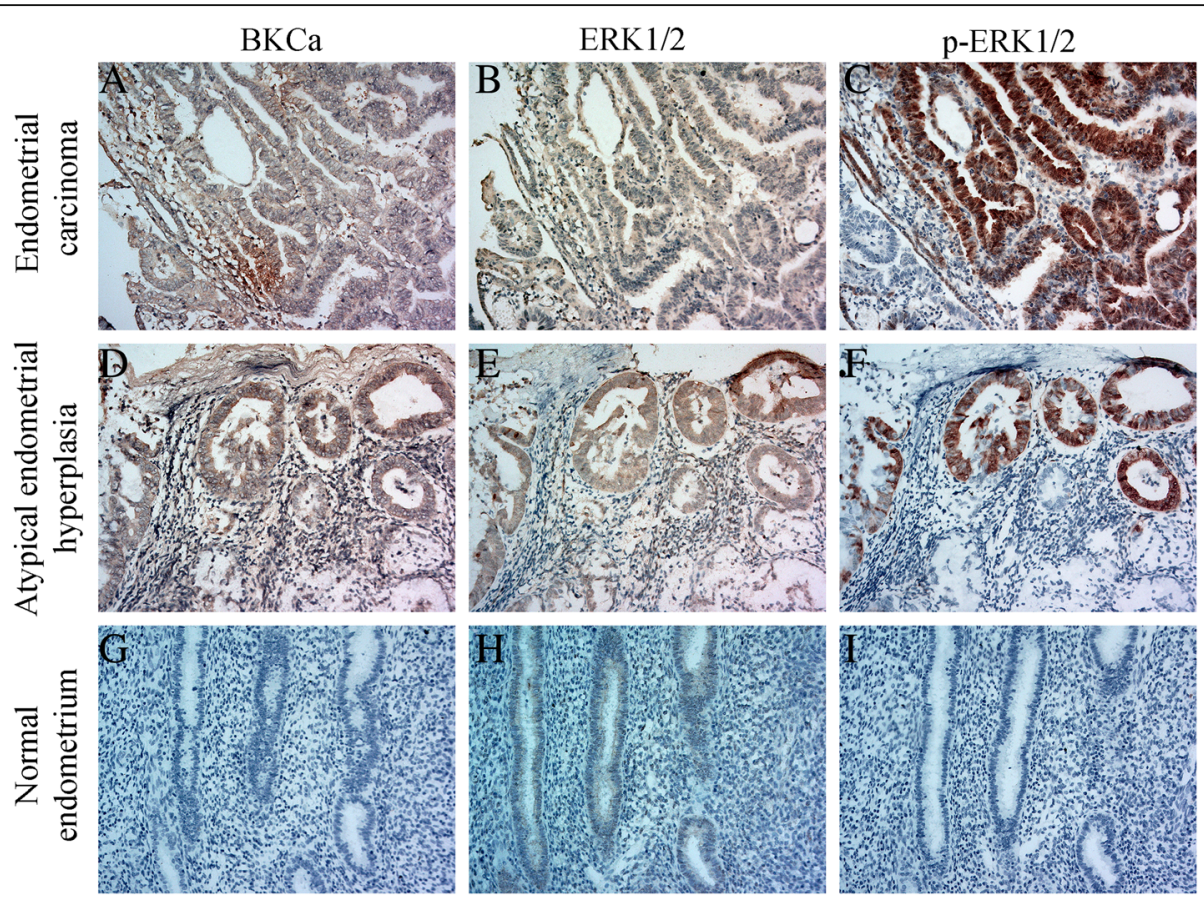

Fig. 3 Representative immunohistochemical staining showed BKCa, ERK $1 / 2$ and p-ERK1/2 expressions in type I endometrial carcinoma tissues and atypical endometrial hyperplasia tissues using serial section technique. Simultaneously increased BKCa, ERK1/2, p-ERK1/2 expressions were observed in the representative cases with type I endometrial cancer (abc) and atypical endometrial hyperplasia tissues (def). The negative expressions of these proteins were shown in normal endometrium (ghi). Magnification $\times 200$

proteins with disease-free survival (DFS) and overall survival (OS) in 185 type I endometrial cancer patients. Significance was tested in univariate and multivariate Cox regression models. Interestingly, the expressions of BKCa and ERK1/2 were not significantly associated with DFS or OS. Only up-regulated expression of p-ERK $1 / 2$ was significantly associated with shorter DFS $\left(p=2.81 \mathrm{E}^{-}\right.$ $\left.{ }^{4}\right)$ and $\operatorname{OS}\left(p=4.18 \mathrm{E}^{-4}\right)$ (Fig. 4). More importantly, univariate and multivariate analysis demonstrated that p-ERK1/2, which could act as downstream effector regulated by $\mathrm{BKCa}$, was an independent prognostic factor of DFS $(p=0.004)$ and OS $(p=0.008)$ in type I endometrial cancer patients (Table.4). This suggests that BKCa and the key downstream effectors p-ERK1/2 could be

Table 1 The aberrant expressions of BKCa, ERK1/2 and p-ERK1/2 in tissue samples of type I endometrial carcinoma, atypical endometrial hyperplasia and normal endometrium

\begin{tabular}{lllll}
\hline Proteins & $\begin{array}{l}\text { Expression } \\
\text { level }\end{array}$ & $\begin{array}{l}\text { Endometrial } \\
\text { adenocarcinoma } \\
(n=185)\end{array}$ & $\begin{array}{l}\text { Atypical endometrial } \\
\text { hyperplasia } \\
(n=38)\end{array}$ & $\begin{array}{l}\text { Normal } \\
\text { endometrium } \\
(n=40)\end{array}$ \\
\hline BKCa & High & 68 & 2 & 2 \\
ERK1/2 & How & 117 & 36 & 38 \\
& Low & 110 & 5 & 2 \\
p-ERK1/ & High & 93 & 33 & 38 \\
2 & Low & 92 & 12 & 1 \\
\hline
\end{tabular}

involved in important signaling pathways in the pathogenesis and development of endometrial adenocarcinoma.

\section{Discussion}

In the present study, we investigated the role of BKCa in the initiation and development of endometrial adenocarcinoma. Our findings indicated that expression of $\mathrm{BKCa}$ in endometrial adenocarcinoma tissues were significantly increased compared to those of normal endometrium or atypical endometrial hyperplasia tissues. Additionally, we also found that knock down of BKCa expression in Ishikawa cells inhibited cell proliferation, migration and invasion, and promoted cell apoptosis, as well as blocking cell cycle progression. BKCa has been previously reported to be elevated in many kinds of cancer. BKCa is overexpressed in prostate cancer [19] and up-regulation of $\mathrm{BKCa}$ promotes proliferation, migration and invasion of prostate cancer cells. On the contrary, down-regulation of BKCa inhibited growth and metastasis of prostate cancer cells. BKCa was also hypothesized to function as oncoproteins in breast cancer [20], with metastatic breast cancer cells reported to exhibit increased BKCa activity, leading to greater invasiveness and migration [21]. Moreover, BKCa has been reported to act as a potential therapeutic target in breast cancer [22]. BKCa action was mainly mediated through forming a functional complex with alphavbeta3 integrin [19] or coupled with 
Table 2 The correlations of the expressions of ERK1/2, p-ERK1/2 and BKCa proteins in tissue samples of type I endometrial carcinoma

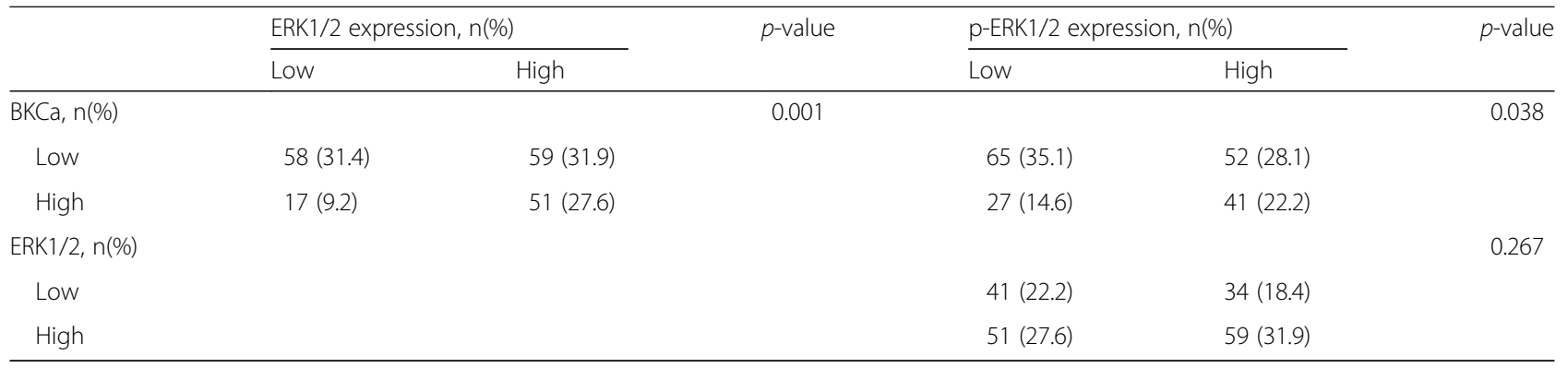

IP3R3 [23] to promote the BKCa activity. There are few studies exploring the relationship between $\mathrm{BKCa}$ and endometrial cancer. Recently using HEC-1-B cancer cell line to investigate the role of $\mathrm{BKCa}$ in endometrial cancer, $\mathrm{Li}$ et al. found that knock down of BKCa significantly inhibited HEC-1-B cell proliferation, migration and tumor growth in vitro and vivo assays [16]. Consistent with the previous reports, our results showed that the expression of $\mathrm{BKCa}$ in endometrial adenocarcinoma tissues were increased significantly, with decreased $\mathrm{BKCa}$ expression could inhibit cancer cell growth and invasion.
It suggested BKCa could act as a potential oncogene in endometrial adenocarcinoma cells. Currently, the alteration and the precise oncogenic mechanisms of BKCa in endometrial adenocarcinoma cells remain unknown.

Accumulating evidence has also confirmed that E2 were important physiological and pathophysiological regulators of uterus and endometrial functions. Moreover, it has been apparent that MEK/ERK pathway is involved in the pathogenesis and development of endometrial cancer acting as the key molecular networkers [24]. E2 could promote the proliferation and stimulate the invasive

Table 3 The correlations between the expressions of BKCa, ERK1/2 and p-ERK1/2 proteins and the clinicopathological parameters in 185 cases with type I endometrial cancer

\begin{tabular}{|c|c|c|c|c|c|c|c|c|c|}
\hline \multirow[t]{2}{*}{ Characteristics } & \multicolumn{2}{|c|}{ BKCa, n (\%) } & \multirow[t]{2}{*}{$p$-value } & \multicolumn{2}{|c|}{ ERK1/2, n (\%) } & \multirow[t]{2}{*}{$p$-value } & \multicolumn{2}{|c|}{ p-ERK1/2, n (\%) } & \multirow[t]{2}{*}{$p$-value } \\
\hline & Low & High & & Low & High & & Low & High & \\
\hline Age & & & 0.119 & & & 0.151 & & & 0.179 \\
\hline$\leq 60$ & $82(44.3)$ & $40(21.6)$ & & $54(29.2)$ & 68(36.8) & & $65(35.1)$ & $57(30.8)$ & \\
\hline$>60$ & $35(18.9)$ & $28(15.1)$ & & 21(11.4) & $42(22.7)$ & & $27(14.6)$ & $36(19.5)$ & \\
\hline FIGO stage & & & 0.004 & & & 0.271 & & & 0.012 \\
\hline$<\|$ & $80(43.2)$ & $32(17.3)$ & & $49(26.5)$ & 63(34.1) & & 64(34.6) & $48(25.9)$ & \\
\hline$\geq \|$ & $37(20.0)$ & $36(19.5)$ & & $26(14.1)$ & $47(25.4)$ & & $28(15.1)$ & $45(24.3)$ & \\
\hline Differentiation & & & 0.733 & & & 0.345 & & & 0.623 \\
\hline Well/moderate & $92(49.7)$ & $52(28.1)$ & & 61(33.0) & 83(44.9) & & 73(39.5) & 71(38.4) & \\
\hline Poor & 25(13.5) & 16(8.6) & & $14(7.6)$ & $27(14.6)$ & & 19(10.3) & $22(11.9)$ & \\
\hline Myometrial invasion & & & 0.958 & & & 0.066 & & & 0.201 \\
\hline$<1 / 2$ & $95(51.4)$ & $55(29.7)$ & & $56(30.3)$ & $94(50.8)$ & & $78(42.2)$ & 72(38.9) & \\
\hline$\geq 1 / 2$ & $22(11.9)$ & $13(7.0)$ & & 19(10.3) & 16(8.6) & & $14(7.6)$ & $21(11.4)$ & \\
\hline Cervical stromal involvement & & & 0.107 & & & 0.457 & & & 0.014 \\
\hline No & $84(45.4)$ & $41(22.2)$ & & $53(28.6)$ & $72(38.9)$ & & $70(37.8)$ & $55(29.7)$ & \\
\hline Yes & $33(17.8)$ & $27(14.6)$ & & 22(11.9) & $38(20.5)$ & & $22(11.9)$ & $38(20.5)$ & \\
\hline LVSI & & & 0.104 & & & 0.183 & & & 0.046 \\
\hline No & $112(60.5)$ & $60(32.4)$ & & 72(38.9) & $100(54.1)$ & & $89(48.1)$ & $83(44.9)$ & \\
\hline Yes & $5(2.7)$ & $8(4.3)$ & & $3(1.6)$ & $10(5.4)$ & & $3(1.6)$ & $10(5.4)$ & \\
\hline LNM & & & 0.011 & & & 0.407 & & & 0.018 \\
\hline No & 114(61.6) & $59(31.9)$ & & 72(38.9) & 101(54.6) & & $90(48.6)$ & $83(44.9)$ & \\
\hline Yes & $3(1.6)$ & $9(4.9)$ & & $3(1.6)$ & $9(4.9)$ & & $2(1.1)$ & $10(5.4)$ & \\
\hline
\end{tabular}




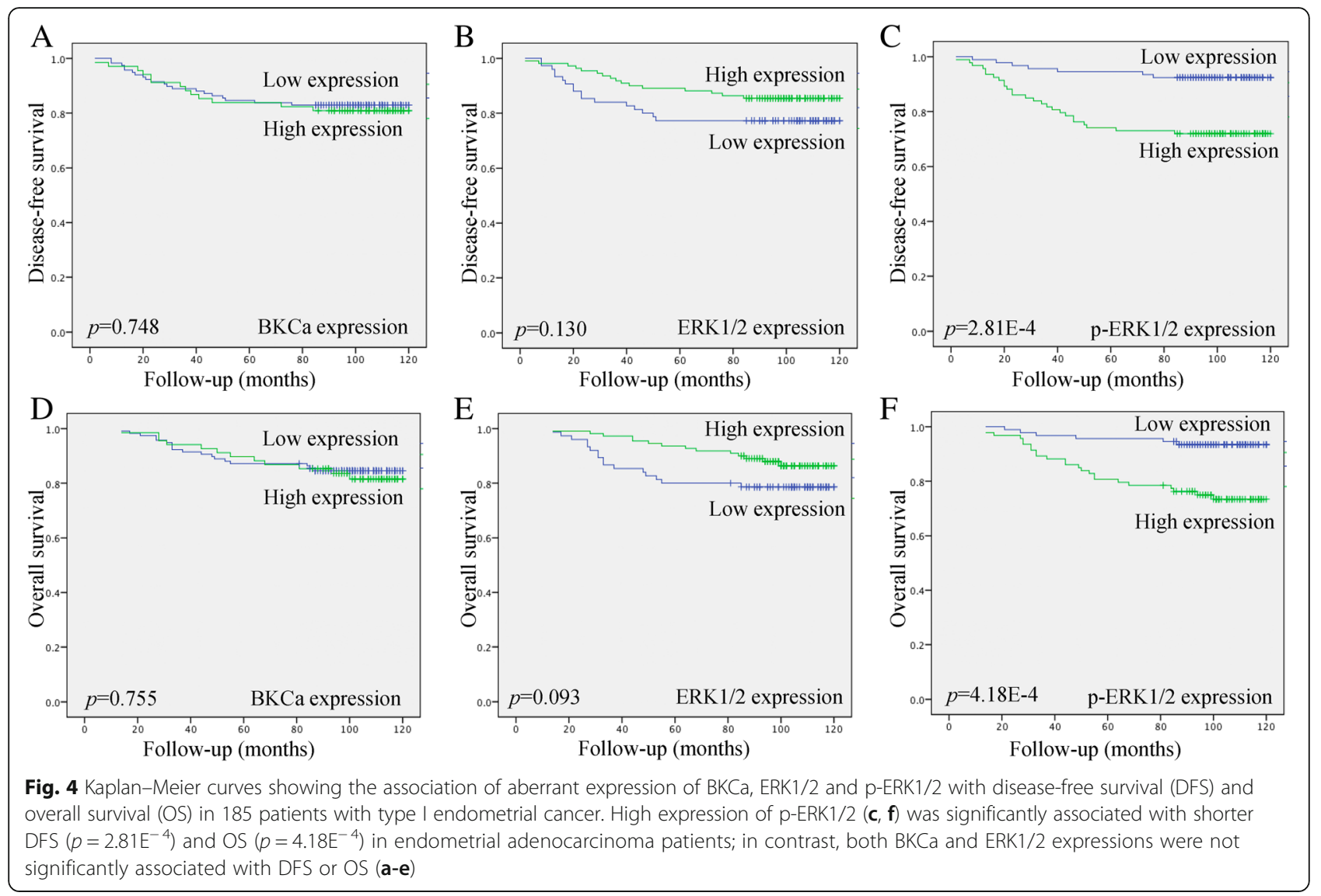

capability of the endometrial cancer cell lines via the GPR30-mediated MEK/ERK pathway [25]. Autocrine motility factor (AMF) was related with the proliferative and metastatic of endometrial carcinoma and MEK-ERK1/2 pathway was involved [26]. As such, the MEK/ERK pathway may have a potential role in sustaining tumorigenic potential and radio-resistance in Ishikawa cells [27]. However, there are currently few reports about the relationship between estrogen and BKCa in E2 activating MEK/ERK pathway. In the study, we found that E2 increased the expression of BKCa protein, prompted cell growth and invasion, and induced the phosphorylation of MEK1/2 and ERK1/2 proteins. More importantly, the reduction of BKCa expression using siRNA in Ishikawa cells after E2 treatment could significantly attenuate the expression of p-MEK1/2 and p-ERK1/2 proteins, as well as cell growth and invasion capabilities induced by E2 stimulation, consequently suggesting that $\mathrm{BKCa}$ at least partially participates in E2 inducing endometrial adenocarcinoma by activating MEK/ERK pathway. A previous report has shown that the G-protein coupled estrogen receptor 1 (GPER1) stimulation, that is activated by estrogen, could result in an increased BKCa channel activity. BKCa is directly activated by estrogens, which have an essential role in cancers of breast [28] and prostate through both genomic and non-genomic mechanisms. Estrogen at physiological concentration enhances BKCa channel activity through CGMP-PKG signaling pathway by stimulating generation of $\mathrm{NO}$ in vascular smooth muscle cells (VSMCs) [29]. Chronic exposure to estrogen also alters BKCa channel function in VSMCs. Estrogen could stimulate the transcriptional promoter activity of the same gene in mouse through activation of estrogen receptor $\alpha(E R \alpha)$ [30] by binding to the estrogen responsive sequences in the promoter of mouse $\alpha$-subunit gene. $17 \beta$-estradiol in an ex vivo tissue culture system augmented BKCa channel activity, which was accompanied by increased protein expression of $\beta 1$ subunit [8], and the similar treatment of ovarectomized guinea pig increased expression of $\alpha$ subunit in aorta [31, 32]. However, on the contrary, exposure of cultured human coronary arterial myocytes to a pharmacological concentration of $17 \beta$-estradiol led to downregulation of $\mathrm{BKCa}$ channels [33]. Currently, the detailed mechanism about how estrogen mediated increase of $\mathrm{BKCa}$ is still not clear. It appears that estrogen augmented expression of $\mathrm{BKCa}$ is species specific or tissue dependent. Though we did not reveal the mechanism about E2 inducing elevated expression of $\mathrm{BKCa}$ in the current study, it may be similar to the previous studies. 
Table 4 Univariate and multivariate analysis of the correlations between prognostic value and disease-free and overall survival rates in 185 patients with type I endometrial cancer

\begin{tabular}{|c|c|c|c|c|c|c|}
\hline \multirow[t]{2}{*}{ Characteristics } & \multicolumn{3}{|c|}{ Disease-free survival } & \multicolumn{3}{|c|}{ Overall survival } \\
\hline & $\overline{\mathrm{HR}}$ & $95 \% \mathrm{Cl}$ & $p$ & $\overline{\mathrm{HR}}$ & $95 \% \mathrm{Cl}$ & $p$ \\
\hline \multicolumn{7}{|l|}{ Univariate analysis } \\
\hline Age & 2.603 & $1.321-5.166$ & 0.006 & 2.777 & $1.348-5.718$ & 0.006 \\
\hline FIGO stage & 2.956 & $1.454-6.011$ & 0.003 & 3.420 & $1.600-7.312$ & 0.002 \\
\hline Differentiation & 5.221 & $2.628-10.375$ & $2.39 \mathrm{E}^{-6}$ & 5.516 & $2.676-11.372$ & $3.72 \mathrm{E}^{-6}$ \\
\hline Myometrial invasion & 4.911 & $2.477-9.738$ & $5.17 \mathrm{E}^{-6}$ & 5.411 & $2.635-11.112$ & $4.25 \mathrm{E}^{-6}$ \\
\hline LVSI & 6.352 & $2.940-13.722$ & $2.55 \mathrm{E}^{-6}$ & 6.675 & $3.046-14.627$ & $2.11 \mathrm{E}^{-6}$ \\
\hline LNM & 14.51 & $6.994-30.103$ & $6.79 \mathrm{E}^{-13}$ & 15.02 & $6.964-32.384$ & $4.84 \mathrm{E}^{-12}$ \\
\hline Cervical stromal involvement & 1.589 & $0.797-3.170$ & 0.188 & 1.932 & $0.942-3.959$ & 0.072 \\
\hline BKCa expression & 1.121 & $0.558-2.253$ & 0.749 & 1.123 & $0.541-2.331$ & 0.756 \\
\hline ERK1/2 expression & 0.594 & $0.300-1.175$ & 0.134 & 0.546 & $0.267-1.120$ & 0.099 \\
\hline p-ERK1/2 expression & 4.149 & $1.800-9.563$ & 0.001 & 4.358 & $1.781-10.664$ & 0.001 \\
\hline \multicolumn{7}{|l|}{ Multivariate analysis } \\
\hline Age & 1.717 & $0.842-3.503$ & 0.137 & 1.912 & $0.909-4.025$ & 0.088 \\
\hline FIGO stage & 1.268 & $0.538-2.986$ & 0.587 & 1.607 & $0.648-3.983$ & 0.306 \\
\hline Differentiation & 3.111 & $1.413-6.851$ & 0.005 & 3.494 & $1.520-8.034$ & 0.003 \\
\hline Myometrial invasion & 3.096 & $1.430-6.703$ & 0.004 & 3.648 & $1.642-8.106$ & 0.001 \\
\hline LVSI & 0.503 & $0.154-1.647$ & 0.256 & 0.635 & $0.196-2.050$ & 0.447 \\
\hline LNM & 5.008 & $1.513-16.573$ & 0.008 & 3.832 & $1.145-12.826$ & 0.029 \\
\hline p-ERK1/2 expression & 3.912 & $1.542-9.927$ & 0.004 & 3.796 & $1.415-10.180$ & 0.008 \\
\hline
\end{tabular}

FIGO International Federation of Gynecology and Obstetrics, LVSI lymph vascular space invasion, LNM lymph node metastasis, HR hazard ratio, 95\% Cl, 95\% confidence interval

It is well established that the occurrence of endometrial adenocarcinoma is mainly stimulated by estrogen, and progresses slowly. The epithelium transforms from normal tissue through atypical endometrial hyperplasia to develop endometrial cancer. Atypical endometrial hyperplasia can be characterized as a pre-cancerous disease, and the majority of them progress to invasive disease if without effective clinical treatment. However, there is a current lack of biomarkers to predict progression to endometrial cancer. In the study, the data showed that the expressions of BKCa, ERK1/2 and p-ERK1/2 were significantly increased in endometrial adenocarcinoma compared to normal endometrium or atypical endometrial hyperplasia tissues. More importantly, only a gradual increase of p-ERK1/2 expression was observed beginning in normal endometrium and continuing through atypical endometrial hyperplasia to endometrial adenocarcinoma. Hence, Increased p-ERK1/2 expression closely related to clinical characteristics and might act as a potential biomarker to predict the occurrence of endometrial adenocarcinoma.

Though the prognosis of early stage endometrial adenocarcinoma with primary surgical resection is relative good, improvement of the five-year survival rate is still the goal of the clinical members. We have known that several molecular alterations had been described in the different types of $\mathrm{EC}$, and these genes involved in the important signaling pathways were key factors related with the prognosis of the disease. The most relevant altered pathways in EC, include PI3K/AKT/mTOR [24], RAS-RAF-MEK-ERK [34], Tyrosine kinase, WNT/ $\beta$-Catenin [35], and TGF- $\beta$ signaling pathways [36]. MEK/ERK pathway is also an important kinase involved in the signal transduction of endometrial carcinoma and act as key targets in many cancer biological target therapies. ERK, as a key effector in MEK/ERK pathway, can be phosphorylated and translocated into the nucleus that inducing activation of downstream transcriptional factors to participate in the regulation of growth, development and differentiation. On the other hand, the level of p-ERK was found to be closely related to the prognosis of gastric cancer, hepatic cancer, and colon cancer. Hence, p-ERK acts as a prognostic factors and key oncogenic gene in different type of malignant cancer, with previous studies reporting that the elevated expression of p-ERK was correlated with later stage, deeper invasion and poor differentiation in endometrial cancer [34]. In the study, we found that expressions of ERK1/2 and p-ERK1/2 were both positive correlated with the expression of $\mathrm{BKCa}$ in 185 cases with type I 
endometrial cancer, and $\mathrm{BKCa}$ could regulate the expression of p-MEK $1 / 2$ and p-ERK $1 / 2$ to influence cell growth and invasion in endometrial cancer cells. The present study is the first time showed possible association of $\mathrm{BKCa}$ with MEK/ERK pathway in endometrial adenocarcinoma. In the study, though BKCa was not an independent prognostic factor, $\mathrm{BKCa}$ could regulate the expression of p-ERK $1 / 2$ that could serve as an independent prognostic predictor of shorter DFS and OS in endometrial adenocarcinoma patients by univariate and multivariate analysis. Taken together, we suggest that BKCa acts as an oncogenic activity membrane molecule and could regulate MEK/ERK pathway to participate in the initiation and development of endometrial adenocarcinoma and influence the prognosis and survival rate.

\section{Conclusions}

In summary, BKCa had been confirmed to be an essential membrane molecule acting as an oncogenic factor in endometrial adenocarcinoma cell and regulate the $\mathrm{p}$ MEK1/2 and p-ERK1/2 proteins expression to participate in cell growth and invasion by E2 stimulation. Therefore, targeting $\mathrm{BKCa}$ by siRNA could effectively inhibit the activity of MEK/ERK pathway and attenuate the cellular behavior induced by E2 treatment. These novel findings promote a better understanding of the functions and mechanisms of BKCa in endometrial adenocarcinoma, and may provide a new approach for the treatment of endometrial adenocarcinoma patients.

\section{Additional files}

Additional file 1: Table S1. The information about the sequences. (DOCX $16 \mathrm{~kb}$ )

Additional file 2: Table S2. The information of the primary antibodies used in the studies. (DOCX $15 \mathrm{~kb}$ )

Additional file 3: Figure S1. 17ß-estradiol (E2) induced an increase in the expression of BKCa in Ishikawa cells and promoted the cell growth and invasion. (A) Western Blot showed that $1 \mathrm{nM}$ E2 treatment significantly increased level of BKCa protein $(p=0.013)$ and the phosphorylation of MEK1/2 $(p=0.049)$ and phosphorylation of ERK1/2 ( $p=0.044$ ) in Ishikawa cells, but had no effect on level of total MEK1/2 and ERK1/2. (B) Exposure to $1 \mathrm{nM}$ E2 promoted cell proliferation rate at $48 \mathrm{~h}$ and $72 \mathrm{~h}$ in Ishikawa cells ( $p=0.019, p=0.011$ ). (C) Apoptosis assay was performed to determine the early and late apoptotic rate induced by E2 treatment in Ishikawa cells. $1 \mathrm{nM}$ E2 reduced the apoptosis rate from $3.11 \pm 0.53 \%$ to $1.30 \pm 0.26 \%(p=0.006)$. (D) FACS was used to analyze the alteration of cell cycle distribution induced by E2 treatment. $1 \mathrm{nM}$ E2 promoted cell cycle progression and induced increased percentage of cells in S phase and decreased number of cells of G1 and G2 $M$ stage percent. ( $E, F) 1 \mathrm{nM} E 2$ also increased the numbers of migration $\left(p=5.2 \mathrm{E}^{-5}\right)$ and invaded $\left(p=4.87 \mathrm{E}^{-4}\right)$ cells significantly in Ishikawa cells. Data (Mean \pm SD, $n=3$ independent experiments). (TIF $51687 \mathrm{~kb}$ )

Additional file 4: Figure S2. Knockdown of BKCa expression using siRNA significantly decreased the phosphorylation level of MEK1/2 $\left(p=2.96 \mathrm{E}^{-4}\right)$ and $\operatorname{ERK} 1 / 2(p=0.001)$ in Ishikawa, but had no effect on level of the total MEK1/2 and ERK1/2 expressions. (TIF $7103 \mathrm{~kb}$ )
Additional file 5: Table S3. The information about the tissue samples of the patients with type I endometrial cancer and the related clinicpathological parameters. (DOCX $16 \mathrm{~kb}$ )

\section{Abbreviations}

BKCa: The large-conductance, voltage-gated, calcium (Ca (2+))-activated potassium channel; DFS: Disease-free survival; E2: 17 -estradiol; EC: Endometrial cancer; ER: Estrogen Receptor; FIGO: The International Federation of Gynecology and Obstetrics; LNM: Lymph node metastasis; LVSI: Lymph vascular space invasion; OS: Overall survival

\section{Acknowledgements}

We thank pathologist CYZ for histological diagnoses of endometrial adenocarcinoma and tissue samples IHC. We thank XJC for technical assistance and JYM for flow cytometry. We also thank International Science Editing for the manuscript editing.

\section{Funding}

The design, data collection, and cellular experiments were supported by Zhejiang Provincial Natural Science Foundation of China (LY18H160004) and National Natural Science Foundation of China (81202066).

Immunohistochemical experiments and data analysis were supported by National Natural Science Foundation of China (81672568). The data interpretation and writing of the manuscript were supported by the Medical and Health Science and Technology Plan Project of Zhejiang Province (2015KYA124).

Availability of data and materials

All data generated and/or analyzed during the current study are available from corresponding author on reasonable request.

\section{Authors' contributions}

Study design: FFW, QC and BHL. Sample collection: QC, GPH and NL. Cellular experiments: FFW, GPH, NL, YL, XDG and BHL. Immunohistochemical experiments: QC, GPH, NL and BHL. Data analysis: FFW, QC, YL, XDG and BHL. Preparation of the manuscript: FFW, QC, GPH, XDG, NL, YL and BHL. Reviewed and commented on the manuscript: FFW, QC, GPH, XDG, NL, YL and BHL. All authors read and approved the final manuscript.

\section{Ethics approval and consent to participate}

The present study was approved by the Institutional Review Board, Women's hospital, School of Medicine, Zhejiang University. Written, informed consent has been given and obtained from all individual participants included in the study.

\section{Consent for publication}

Not applicable.

\section{Competing interests}

The authors declare that they have no competing interests.

\section{Publisher's Note}

Springer Nature remains neutral with regard to jurisdictional claims in published maps and institutional affiliations.

\section{Author details}

'Department of Gynecologic Oncology, Women's Hospital, Zhejiang University, School of Medicine, Xueshi Road 1, Hangzhou, Zhejiang 310006, People's Republic of China. 'Department of Pathology, Women's Hospital, Zhejiang University, School of Medicine, Xueshi Road 1, Hangzhou, Zhejiang 310006, People's Republic of China.

Received: 25 April 2018 Accepted: 31 October 2018

Published online: 16 November 2018

References

1. Morice P, Leary A, Creutzberg C, Abu-Rustum N, Darai E. Endometrial cancer. Lancet. 2016:387:1094-108.

2. Siufi DF, Siufi Neto J, Abrao MS, Favero G. Lymphadenectomy in early stage endometrial cancer: a critical review of the current literature. Tumori. 2014; 100:477-85 
3. Tong JS, Zhang QH, Wang ZB, Li S, Yang CR, Fu XQ, et al. ER-alpha36, a novel variant of ER-alpha, mediates estrogen-stimulated proliferation of endometrial carcinoma cells via the PKCdelta/ERK pathway. PLoS One. 2010; 5:e15408.

4. Koo KH, Jeong WJ, Cho YH, Park JC, Min do S, Choi KY. K-Ras stabilization by estrogen via PKCdelta is involved in endometrial tumorigenesis. Oncotarget. 2015;6:21328-40.

5. Su T, Qu JJ, Wang K, Li BL, Zhao D, Zhu YP, et al. Cross-talk between p21activated kinase 4 and ERalpha signaling triggers endometrial cancer cell proliferation. Oncotarget. 2017:8:68083-94.

6. Hou S, Heinemann SH, Hoshi T. Modulation of BKCa channel gating by endogenous signaling molecules. Physiology (Bethesda). 2009;24:26-35.

7. Lu R, Alioua A, Kumar Y, Eghbali M, Stefani E, Toro L. MaxiK channel partners: physiological impact. J Physiol. 2006;570:65-72.

8. Hu XQ, Dasgupta C, Chen M, Xiao D, Huang X, Han L, et al. Pregnancy reprograms large-conductance $\mathrm{Ca} 2+$-activated $\mathrm{K}+$ channel in uterine arteries: roles of ten-eleven translocation Methylcytosine dioxygenase 1mediated active demethylation. Hypertension. 2017;69(6):1181-191.

9. Bloch M, Ousingsawat J, Simon R, Schraml P, Gasser TC, Mihatsch MJ, et al. KCNMA1 gene amplification promotes tumor cell proliferation in human prostate cancer. Oncogene. 2007;26:2525-34.

10. Cambien B, Rezzonico R, Vitale S, Rouzaire-Dubois B, Dubois JM, Barthel R, et al. Silencing of hSlo potassium channels in human osteosarcoma cells promotes tumorigenesis. Int J Cancer. 2008;123:365-71.

11. Oeggerli M, Tian Y, Ruiz C, Wijker B, Sauter G, Obermann E, et al. Role of KCNMA1 in breast cancer. PLoS One. 2012;7:e41664.

12. Ma G, Liu H, Hua Q, Wang M, Du M, Lin Y, et al. KCNMA1 cooperating with PTK2 is a novel tumor suppressor in gastric cancer and is associated with disease outcome. Mol Cancer. 2017;16:46.

13. Shi JH, Jin L, Leng JH, Lang $J H$. Expression of potassium channels in uterine smooth muscle cells from patients with Adenomyosis. Chin Med J. 2016; 129:200-5.

14. Lorca RA, Prabagaran M, England SK. Functional insights into modulation of BKCa channel activity to alter myometrial contractility. Front Physiol. 2014;5:289.

15. Gao L, Cong B, Zhang L, Ni X. Expression of the calcium-activated potassium channel in upper and lower segment human myometrium during pregnancy and parturition. Reprod Biol Endocrinol. 2009:7:27.

16. Li N, Liu L, Li G, Xia M, Du C, Zheng Z. The role of BKCa in endometrial cancer HEC-1-B cell proliferation and migration. Gene. 2018;655:42-7.

17. Wang F, Li Y, Zhou J, Xu J, Peng C, Ye F, et al. miR-375 is down-regulated in squamous cervical cancer and inhibits cell migration and invasion via targeting transcription factor SP1. Am J Pathol. 2011;179:2580-8

18. Li B, Shi H, Wang F, Hong D, Lv W, Xie X, et al. Expression of E-, P- and Ncadherin and its clinical significance in cervical squamous cell carcinoma and precancerous lesions. PLoS One. 2016;11:e0155910.

19. Du C, Zheng Z, Li D, Chen L, Li N, Yi X, et al. BKCa promotes growth and metastasis of prostate cancer through facilitating the coupling between alphavbeta3 integrin and FAK. Oncotarget. 2016;7:40174-88.

20. Schickling BM, England SK, Aykin-Burns N, Norian LA, Leslie KK, FriedenKorovkina VP. BKCa channel inhibitor modulates the tumorigenic ability of hormone-independent breast cancer cells via the Wnt pathway. Oncol Rep. 2015;33:533-8

21. Khaitan D, Sankpal UT, Weksler B, Meister EA, Romero IA, Couraud PO, et al. Role of KCNMA1 gene in breast cancer invasion and metastasis to brain. BMC Cancer. 2009;9:258.

22. Du C, Chen L, Zhang H, Wang Z, Liu W, Xie X, et al. Caveolin-1 limits the contribution of BKCa channel to MCF-7 breast cancer cell proliferation and invasion. Int J Mol Sci. 2014;15:20706-22.

23. Mound A, Rodat-Despoix L, Bougarn S, Ouadid-Ahidouch H, Matifat F. Molecular interaction and functional coupling between type 3 inositol 1,4,5trisphosphate receptor and BKCa channel stimulate breast cancer cell proliferation. Eur J Cancer. 2013;49:3738-51.

24. Eritja N, Yeramian A, Chen BJ, Llobet-Navas D, Ortega E, Colas E, et al. Endometrial carcinoma: specific targeted pathways. Adv Exp Med Biol. 2017; 943:149-207.

25. He YY, Cai B, Yang YX, Liu XL, Wan XP. Estrogenic G protein-coupled receptor 30 signaling is involved in regulation of endometrial carcinoma by promoting proliferation, invasion potential, and interleukin- 6 secretion via the MEK/ERK mitogen-activated protein kinase pathway. Cancer Sci. 2009; 100:1051-61.
26. Li Y, Jia Y, Che Q, Zhou Q, Wang K, Wan XP. AMF/PGl-mediated tumorigenesis through MAPK-ERK signaling in endometrial carcinoma. Oncotarget. 2015;6:26373-87.

27. Marampon F, Gravina GL, Popov VM, Scarsella L, Festuccia C, La Verghetta $M E$, et al. Close correlation between MEK/ERK and Aurora-B signaling pathways in sustaining tumorigenic potential and radioresistance of gynecological cancer cell lines. Int J Oncol. 2014;44:285-94.

28. Coiret G, Borowiec AS, Mariot P, Ouadid-Ahidouch H, Matifat F. The antiestrogen tamoxifen activates BK channels and stimulates proliferation of MCF-7 breast cancer cells. Mol Pharmacol. 2007;71:843-51.

29. Ambroisine ML, Favre J, Oliviero P, Rodriguez C, Gao J, Thuillez C, et al. Aldosterone-induced coronary dysfunction in transgenic mice involves the calcium-activated potassium (BKCa) channels of vascular smooth muscle cells. Circulation. 2007;116:2435-43.

30. Kundu P, Alioua A, Stefani E, Toro L. Regulation of mouse Slo gene expression: multiple promoters, transcription start sites, and genomic action of estrogen. J Biol Chem. 2007;282:27478-92.

31. Jamali K, Naylor BR, Kelly MJ, Ronnekleiv OK. Effect of 17beta-estradiol on mRNA expression of large- conductance, voltage-dependent, and calciumactivated potassium channel alpha and beta subunits in Guinea pig. Endocrine. 2003;20:227-37.

32. Nishimura I, Ui-Tei K, Saigo K, Ishii H, Sakuma Y, Kato M. 17beta-estradiol at physiological concentrations augments $\mathrm{Ca}(2+)$-activated $\mathrm{K}+$ currents via estrogen receptor beta in the gonadotropin-releasing hormone neuronal cell line GT1-7. Endocrinology. 2008;149:774-82.

33. Korovkina VP, Brainard AM, Ismail P, Schmidt TJ, England SK. Estradiol binding to maxi-K channels induces their down-regulation via proteasomal degradation. J Biol Chem. 2004;279:1217-23.

34. Mizumoto Y, Kyo S, Mori N, Sakaguchi J, Ohno S, Maida Y, et al. Activation of ERK1/2 occurs independently of KRAS or BRAF status in endometrial cancer and is associated with favorable prognosis. Cancer Sci. 2007;98:652-8.

35. Zhao $Y$, Yang $Y$, Trovik J, Sun $K$, Zhou L, Jiang $P$, et al. A novel wnt regulatory axis in endometrioid endometrial cancer. Cancer Res. 2014;74: 5103-17.

36. Mhawech-Fauceglia P, Kesterson J, Wang D, Akers S, DuPont NC, Clark $\mathrm{K}$, et al. Expression and clinical significance of the transforming growth factor-beta signalling pathway in endometrial cancer. Histopathology. 2011:59:63-72.

\section{Ready to submit your research? Choose BMC and benefit from:}

- fast, convenient online submission

- thorough peer review by experienced researchers in your field

- rapid publication on acceptance

- support for research data, including large and complex data types

- gold Open Access which fosters wider collaboration and increased citations

- maximum visibility for your research: over $100 \mathrm{M}$ website views per year

At $\mathrm{BMC}$, research is always in progress.

Learn more biomedcentral.com/submissions 